\title{
Case study of the effects of the conventional concrete carbonating produced in three different cement factorys
}

\author{
Joseci Oliveira de Holanda', José Roberto Abreu², Darlei dos Anjos Lavor ${ }^{3}$
}

\author{
${ }^{1}$ Estudante de Graduação de Engenharia Civil Pelo Centro Universitário do Norte (UNINORTE/Laureate); \\ ${ }^{2}$ Professor do Curso De Engenharia Civil do Centro Universitário do Norte (UNINORTE/Laureate); \\ ${ }^{3}$ Técnico de Laboratório (Laboratorista) do Centro Universitário do Norte (UNINORTE/Laureate) \\ Email: joseci.holanda@Gmail.com, darleilavor27@gmail.com
}

Received: September $13^{\text {th }}, 2016$

Accepted: October $28^{\text {th }}, 2016$

Published: December $22^{\text {th }}, 2016$

Copyright (C2016 by authors and Institute of Technology Galileo of Amazon (ITEGAM) This work is licensed under the Creative Commons Attribution International License (CC BY 4.0).

http://creativecommons.org/licenses/by/4.0/ (c) (i) (2) (2) Open Acces:

\section{Case study of the effects of the conventional concrete carbonating produced in three different cement factorys}

\begin{abstract}
Currently, the most consumed material in the world is the cement. The material that makes up the concrete is a chemical compound that undergoes several changes depending on the materials used and the conditions under which they are presented. Reinforced concrete is the material that offers more pathologies in the structures because of the oxidation of hardware due to bad weather. One of the types of pathology that this concrete offers are infiltrations causing fissures or cracks in the structure. One of the processes that can help the pathological development of this material is its carbonation. This research is based on the immediate prevention of Readymix concrete produced in the city of Manaus, through the study of the application of the chemical phenolphthalein reagent to identify the period of carbonation. For that to happen, will be studied three concrete production plants within the territory of the municipality in order to understand the reasons for the accelerated carbonation.
\end{abstract}

Keywords: Concrete, Carbonation, Pathology.

\section{Estudo de caso dos efeitos da carbonatação do concreto convencional produzido em três usinas distintas}

\begin{abstract}
RESUMO
Atualmente, o material mais consumido no mundo é o cimento. Esse material que compõe o concreto é um composto químico que sofre várias alterações dependendo dos materiais utilizados e das condições em que eles se apresentam. O concreto armado é o material que mais apresenta patologias nas estruturas por causa da oxidação das ferragens devido às intempéries. Um dos tipos de patologia que esse concreto apresenta são infiltrações causando fissuras ou rachaduras na estrutura. Um dos processos que pode ajudar no desenvolvimento patológico desse material é a sua carbonatação. Esta pesquisa baseia-se na prevenção de imediato, do concreto usinado produzido na cidade de Manaus, através do estudo da aplicação do reagente químico de fenolftaleína para identificar o período da carbonatação. Para que isso aconteça, serão estudadas três usinas de produção de concreto dentro do território do município para entender os motivos dessa carbonatação acelerada.
\end{abstract}

Palavras chaves: Concreto, Carbonatação, Patologia.

\section{INTRODUÇÃO}

As causas patológicas do concreto têm uma relação bastante extensa em função de inúmeros fatores que podem influenciá-la.
Apesar das várias preocupações sobre o concreto e sua dosagem, existem também determinadas inquietações desse material após o seu endurecimento, uma delas é chamada de carbonatação. [1] A carbonatação é um dos mecanismos mais correntes de deterioração 
do betão armado. Sua reação acontece através do dióxido de carbono presente no ar que penetra nos poros do betão e reage com o hidróxido de cálcio formando carbonato de cálcio e água. Esta reação é acompanhada pela redução da alcalinidade do betão [2] .A previsão da vida útil da estrutura, deve ser baseada no conhecimento dos mecanismos de degradação, bem como nas velocidades de reações químicas decorrentes.

Toda essa contextualização sobre carbonatação fez pensar-se que, o ideal seria uma avaliação visual da aceleração dessa reação através do indicador químico de fenolftaleína, já que em algumas literaturas é aplicada uma medição de profundidade. Então, diante desses aspectos, o presente projeto vem contribuir, para melhor compreensão sobre o tema abordado, a importância dos prováveis transtornos ocorridos quando o concreto incide no processo de carbonatação. O objetivo é analisar os efeitos causados pela carbonatação do concreto do tipo convencional e estabelecer os principais fatores que facilitam nesse processo, assim como definir os prejuízos que podem causar em uma estrutura de concreto armado. Enfatiza-se que, ainda nesse mesmo estudo foram selecionadas três tipos de usinas produtoras de concreto convencional para que fosse iniciado esse estudo.

A verificação de que as usinas atendem os padrões normativos da Associação Brasileira de Normas Técnicas (ABNT), foram de fundamental importância. A finalidade deste projeto possibilitará uma fonte de informações e dados que permitirá conhecer os procedimentos mais indicados e os cuidados da sua implantação para ter em vista as melhorias do material comercializado e minimizar os custos desnecessários. Outra exemplificação a ser destacada é a observação de velocidade da carbonatação nos corpos de prova de concreto e, diagnosticar a qualidade dos mesmos produzidos em três usinas de concreto da cidade de Manaus.

\section{REVISÃO BIBLIOGRÁFICA}

Primeiramente, a pesquisa bibliográfica foi realizada através dos estudos sobre a carbonatação do concreto para que fosse desenvolvido o tema sugerido. Fazem parte do escopo deste projeto, as literaturas com estudos teóricos, tais quais: os artigos científicos de publicações do Instituto Brasileiro de Concreto (IBRACON), assim como as especificações, os procedimentos e os métodos de ensaios da Associação Brasileira de Normas técnicas (ABNT), para que aprimorasse, dando-se destaque aos subsídios de caracterização da qualidade de concreto tanto em estado fresco quanto no estado endurecido. A pesquisa também foi mais além, através da internet onde se utilizou alguns elementos e dados publicados das revistas eletrônicas, de revistas científicas e dos sites com as informações referentes ao assunto sugerido.

\section{II.1 DETALHAMENTO SOBRE CARBONATAÇÃO DO CONCRETO E OS FATORES QUE A INFLUENCIAM}

A carbonatação [3] é um dos mecanismos mais ocorrentes de deterioração do concreto armado. O processo, felizmente é lento e pode ser esclarecido por causa da hidratação crescente da pasta de cimento. O dióxido de carbono que atua no ar adentra nos poros úmidos do concreto e reage com o hidróxido de cálcio e forma o carbonato de cálcio, daí o nome de carbonatação. Este processo é seguido pela redução da alcalinidade do concreto juntamente com várias etapas envolvendo diversas reações secundárias [4].

Para [5] os materiais metálicos, quando expostos a alguns meios corrosivos, tendem a corroer. Sendo que em alguns destes materiais a oxidação é benéfica. Trata-se da oxidação do cromo e do alumínio, fenômeno conhecido como passivação, que ocorre na presença de oxigênio, e permiti com isso, a formação de óxido de cromo e de alumínio. Em ambos agentes forma-se um filme de óxido de excelente resistência a alguns meios corrosivos. [5] Esse processo de passivação é um fenômeno superficial e bastante complexo, consequentemente, as tentativas de explicá-lo são geralmente restringidas às distintas partes do processo. É um processo natural, o qual pode ser entendido como sendo a reação que ocorre entre as espécies metálicas e as substâncias contidas nesse meio. Essa reação de passivação também pode ocorrer à temperatura ambiente e formar produtos de oxidação, que agem na proteção do metal, para tornar essa superfície mais estável ao meio.

Segundo [6] Afirmam que, os fatores controladores do avanço da carbonatação podem ser associados a dois grupos. $\mathrm{O}$ primeiro é formado pelas ações de origem externa, ou seja, condições ambientais do local onde está inserida a estrutura de concreto; e o segundo depende das características intrínsecas do concreto. Um importante fator que também influencia na carbonatação é a quantidade de $\mathrm{CO} 2$ disponível para a reação. Quanto maior a concentração de $\mathrm{CO} 2$ disponível no meio ambiente, mais rápido ocorre à reação de carbonatação, e consequentemente a retração [7]; com esta demonstrada na tabela 1 .

Tabela 1: Principais fatores que interveem no avanço da carbonatação do concreto.

\begin{tabular}{|c|c|l|}
\hline GRUPO & AÇÃO & FATORES INTERVENIENTES \\
\hline \multirow{2}{*}{ A } & EXTERNA & $>$ Temperatura \\
& $>$ Umidade relativa do ar \\
& Condições ambientais & $>$ Concentração de CO2 \\
\hline \multirow{2}{*}{ B } & & $>$ Relação águal cimento \\
& & $>$ Álcalis \\
& INTERNA & $>$ Agregado \\
& Características do concreto & $>$ Zona de transição \\
& & $>$ Cura \\
& & \\
& &
\end{tabular}

Fonte: Helene, (1998). 
O processo de carbonatação do concreto é bastante complexo e depende de algumas reações seletivas para que esse mecanismo se desenvolva. Estudos já comprovam a influência do concreto na carbonatação e indicam alguns fatores que ajudam a acelerar esse processo. Essa ação pode ter fatores intervenientes que dependem das condições externas e internas da estrutura.

\section{MATERIAIS E MÉTODOS}

\section{III.1 ETAPAS DE CAMPO:}

Este item corresponde aos métodos e procedimentos das coletas para verificar os processos tanto da qualidade dos materiais componentes dos concretos das usinas quanto à fabricação do mesmo em estado fresco. $\mathrm{O}$ ensejo deste projeto está vinculado com todos os padrões normativos determinados pela ABNT e possibilita um melhor entendimento para o objetivo final deste projeto. Para isso, abaixo, ter-se-á as normas que regem esses procedimentos das análises realizadas.

a) NBR 12654/ 92 - Controle tecnológico de materiais componentes do concreto.

b) NBR 12655/ 06 - Concreto de cimento Portland Preparo, controle e recebimento.

c) NBR NM 033/98 - Concreto - Amostragem de concreto fresco [8].

d) NBR 5738/ 03 - Procedimentos para moldagem e cura de corpos de prova de concreto [9].

\section{III.2 ETAPAS DE LABORATÓRIO:}

Abaixo está a relação de cada etapa do processo de análise do concreto em laboratório até a observação pós-aplicação do indicador químico fenolftaleína para verificar a carbonatação do concreto produzido nas usinas especificadas nesse projeto. Os corpos de prova foram fraturados, limpos e aplicados o indicador químico fenolftaleína de $6 \%$, que determina se o concreto está no processo de carbonatação ou não. O indicador químico foi aplicado na parte interna dos corpos de prova.

a) NBR 5738/ 94 - Moldagem e cura de corpos-deprova cilíndricos ou prismáticos de concreto.

b) NBR 5739/94 - Concreto - Ensaio de compressão de corpos-de-prova cilíndricos.

c) Preparação para a aplicação do indicador químico fenolftaleína

d) Aplicação do indicador químico fenolftaleína

\section{RESULTADOS E DISCUSSÕES}

Nesse item, serão analisados os resultados do indicador químico de fenolftaleína nos concretos das usinas 1,2 e 3 referente aos dias 3,14, 28, 42 e 52 de observação para a verificação da carbonatação do concreto.

\section{IV.1 MEDIÇÃO DO INDICADOR QUÍMICO DE FENOLFTALEÍNA}

A profundidade de carbonatação foi acometido com fenolftaleína, um indicador químico de $\mathrm{pH}$. Uma vez que a carbonatação reduz o pH da pasta de cimento. De acordo com a coloração da amostra atacada com fenolftaleína é possível determinar até onde a carbonatação ocorreu.

Após a aplicação do indicador químico de fenolftaleína, nota-se que na figura 01, o processo de carbonatação é lento e quase imperceptível. Ainda na figura 1, abaixo, observa-se que na Usina 10 indicador químico ainda está com a cor vibrante, apesar da figura não ter uma visão tridimensional; já nas Usinas 02 e 03, nota-se alguns pontos mais claros, o que se pode afirmar que o processo de cabonatação já esta iniciado somente com 3 dias de aplicação do indicador químico.

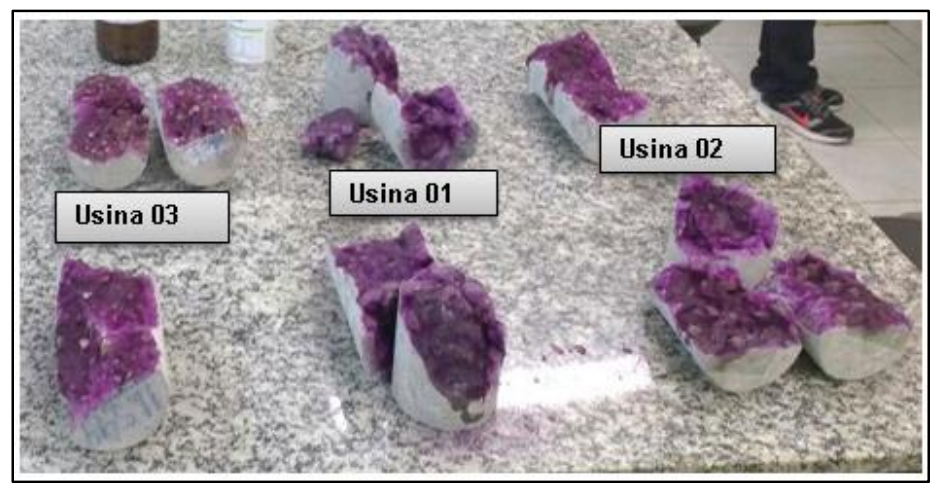

Figura 1: $3^{\circ}$ dia de observação após a aplicação do indicador químico de fenolftaleína.

Fonte: Autores, (2016).

No décimo quarto dia, a presença da carbonatação já é visivelmente notada, principalmente nas Usinas 1 e 2, da figura 02 . Na Usina 3, não se descarta a possibilidade de carbonatação, observa-se que na figura 2 da Usina 3, o processo da reação está no centro e pelas laterais das partes do corpo de prova fraturado. $\mathrm{O}$ processo de carbonatação nessa fase está misto.

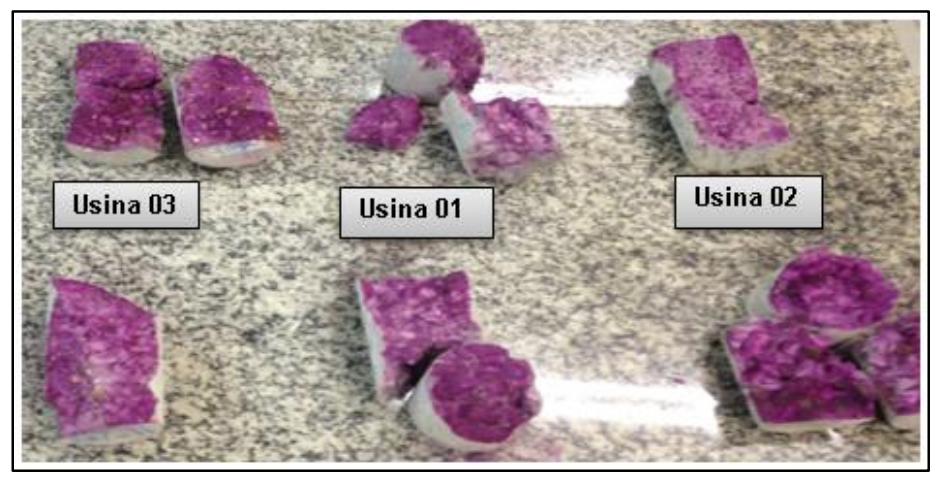

Figura 2: $14^{\circ}$ dia de observação após a aplicação do indicador químico de fenolftaleína.

Fonte: Autores, (2016).

No vigésimo oitavo dia, a presença da carbonatação é maior e mais notada entre os corpos de prova das três usinas distintas escolhidas para esta análise. Na figura 3, as partes mais claras nos corpos de prova das Usinas 1, 2 e 3 mostram que o processo de carbonatação estende-se por quase todos os corpos de prova.

As Usinas 2 e 3 apresentam a reação do indicador químico em pontos específicos como na Usina 2, no canto superior direito da metade do corpo de prova fraturado da figura 3 e a Usina 3, no canto inferior esquerdo da mesma figura. 


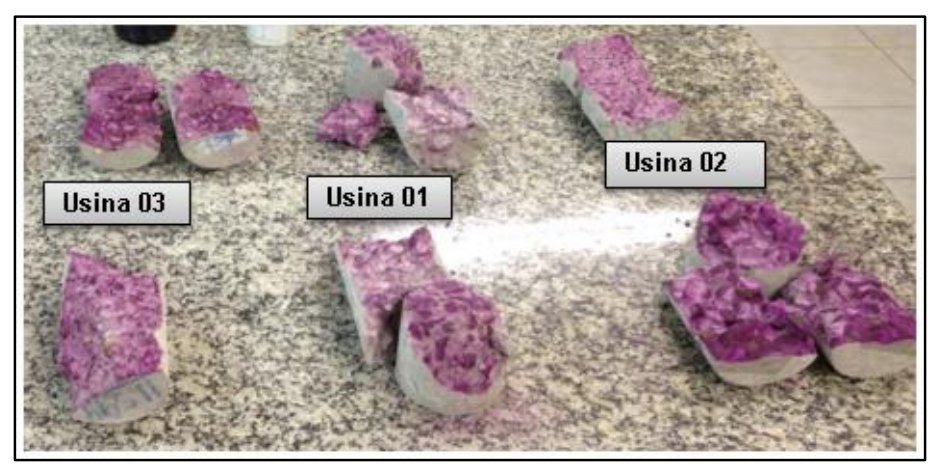

Figura 3: $28^{\circ}$ dia de observação dos corpos de prova com o indicador químico de fenolftaleína aplicado neles.

Fonte: Autores, (2016).

As partes mais claras dos corpos de prova são quando o indicador químico de fenolftaleína se aspersa, já são indícios de carbonatação. As partes que mantem a cor de vermelho-carfim significam que os corpos de prova não estão carbonatados. A figura 4, abaixo, mostra a presença da carbonatação ainda maior aos quarenta e dois dias de observação. Ainda na figura 04, notase que as Usinas 2 e 3 são as que menos apresentam em determinados pontos e a metade da fratura dos corpos de prova.

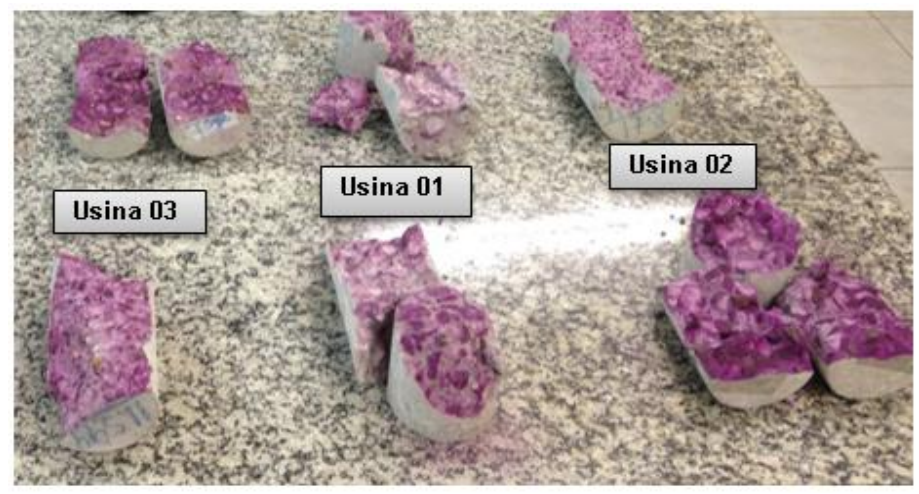

Figura 4: $42^{\circ}$ dia de observação após a aplicação do indicador químico de fenolftaleína.

Fonte: Autores, (2016).

No quinquagésimo segundo e último dia de observação dos corpos de prova com o indicador químico de fenolftaleína, observa-se que a Usina 1 da figura 5, foi a que mais apresentou a carbonatação do concreto.

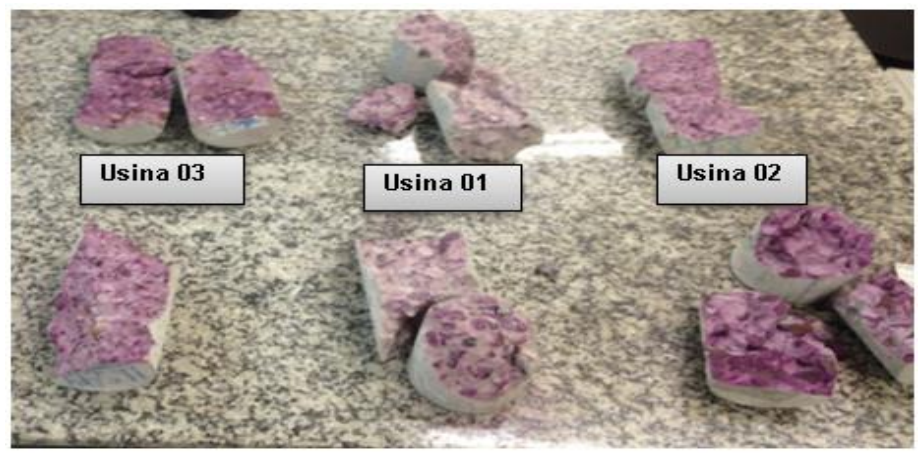

Figura 5: $52^{\circ}$ e último dia de observação após a aplicação do indicador químico de fenolftaleína.

Fonte: Autores, (2016).
De acordo com as análises realizadas, conclui-se que todas as amostragens, de acordo com o processo de observação, desde a aplicação do indicador químico até o último dia de observação estabelecido; tiveram suas pastas de cimento carbonatadas. Toda essa observação indica que o processo de carbonatação do concreto é bem mais rápido do que se imaginava e o tempo de vida útil do concreto armado é bem menor do que se pode determinar.

\section{CONCLUSÕES}

Em virtude dos resultados apresentados no item 4 deste projeto, pode-se concluir que:

Além da distribuição de tamanho de partículas, fatores como quantidade de material misturado, ou a forma da partícula e área superficial, influenciam no arranjo entre materiais granulares em uma mistura, resultaram em misturas com maior porosidade. Este comportamento pode ser devido à má dispersão destas partículas pequenas, formando aglomerados que favoreceram a formação de vazios. As pastas com maior índice de vazios apresentaram maior absorção de água, e desta forma a profundidade de carbonatação foi maior nestas matrizes. O maior volume de poros favorece a difusão do dióxido de carbono para o interior do compósito, acelerando o fenômeno da carbonatação.

Para diminuir os vazios entre os grãos dos agregados é necessário dispor de um controle mais rígido, principalmente no adensamento, com a intensão de eliminar o índice de vazios entre os grãos dos agregados na pasta de cimento, para não oferecer recinto que acontecer a reação química de carbonatação do concreto.

\section{REFERÊNCIAS}

[1] LABORATÓRIO NACIONAL DE ENGENHARIA CIVIL. F029: Determinação da profundidade de carbonatação de betões, argamassas e outros materiais cimentícios. DISPONÍVEL EM: http://www.ozdiagnostico.pt/fichas/1F029.pdf Acesso em Jan/2016.

[2] CLIFTON, J.R. Predicting the servisse life of concrete. ACI Journal, v. 90, nº 6, 1993.

[3] BLOG ALDO WERLE: Carbonatação do concretoFenolftaleína. 2012. DISPONÍVEL EM: http://www.aldowerle.blogspot.com.br/2012/09/carbonatacao-doconcreto-fenolftaleina.html Acesso em Jan/2016.

[4] CASCUDO, O. O controle da corrosão de armaduras em concreto: inspeção e técnicas eletroquímicas. $1^{\mathrm{a}}$ ed. Goiânia, GO: Editora UFG, 1997. 237p.

[5] RODRIGUEZ, R. M. H. P. Formação de óxidos nos revestimentos de alumínio depositados por aspersão térmica. Curitiba-PR: UFP, 2003. Tese (Doutorado)-Programa Interdisciplinar de Pós Graduação em Engenharia, na Área de Materiais, Setor Tecnologia. Universidade Federal do Paraná, 2003. 134p. 
[6] HELENE, P. R. L., NUNES, F. L. Influência da dosagem na carbonatação dos concretos. Tese de Livre Docência, EPUSP, São Paulo, 1998.

[7] MINDESS, S. Concrete. Englewood Cliffs, N.J: Prentice-Hall, 1981.

[8] ASSOCIAÇÃO BRASILEIRA DE NORMAS TÉCNICAS. NBR NM 033: Concreto - Amostragem de concreto fresco. Rio de Janeiro, 1998.

[9] ASSOCIAÇÃO BRASILEIRA DE NORMAS TÉCNICAS. NBR 5738: Concreto - Procedimento para moldagem e cura de corpos-de-prova. Rio de Janeiro, 2003. 